\title{
Effect of Heterogeneity of Porous Media on Gas Permeation and Entrapment*
}

\author{
Yohei Mikami', Yoshihiro Deguchi'1,Tetsuya Suekane² \\ ${ }^{1}$ The University of Tokushima, Tokushima, Japan \\ ${ }^{2}$ Tokyo Institute of Technology, Yokohama, Japan \\ Email: mkm.yohei.17g@gmail.com
}

Received 15 March 2014; revised 30 April 2014; accepted 21 May 2014

Copyright (C) 2014 by authors and Scientific Research Publishing Inc.

This work is licensed under the Creative Commons Attribution International License (CC BY).

http://creativecommons.org/licenses/by/4.0/

(c) (i) Open Access

\begin{abstract}
Capillary trapping prevents the migration of $\mathrm{CO}_{2}$ in reservoirs due to buoyancy. The residual gas saturation is strongly influenced by the gas saturation after gas injection. In this study, we have investigated the effect of stratified structure of heterogeneous porous media on gas permeation and entrapment. Experiments were carried out at a laboratory condition for a nitrogen-water system with the packed beds of glass beads with various diameters which modeled stratified porous media. In the case of parallel structure, the injected gas selectively percolated into permeable layers. The gas permeation can hardly occur for the less permeable layers because of the capillary entrance pressure. In the case of serial structure, the interface of porous structure hindered the migration of gas across it, because of the capillary entrance pressure. When the gas percolated in the permeable layers, capillary fingering was developed in the layers. However, when the tip of finger reached the interface, fingers grew in tangential directions until the pressure built up to overcome the capillary entrance pressure. As a result, high gas saturation was achieved in the permeable layers of both upward and downward gas injections.
\end{abstract}

\section{Keywords}

Carbon Dioxide Capture and Storage (CCS), Residual Gas Trapping, X-Ray CT, Capillarity

\section{Introduction}

Recently, global warming becomes one of the worldwide issues. Its solution may include the carbon dioxide capture and storage (CCS) technology that is one of the possible options to mitigate the global warming of the earth. In the CCS technology, the residual gas trapping [1]-[10] is one of the cardinal trapping-mechanisms to mitigate the migration of $\mathrm{CO}_{2}$ due to buoyancy as well as the physical trapping by the cap rock, dissolution in *Short paper.

How to cite this paper: Mikami, Y., Deguchi, Y. and Suekane, T. (2014) Effect of Heterogeneity of Porous Media on Gas Permeation and Entrapment. Journal of Flow Control, Measurement \& Visualization, 2, 110-119. 
water [10]-[17], and mineralization [18] [19].

The residual gas saturation, which is defined as the volume ratio of trapped $\mathrm{CO}_{2}$ to the pore space, is affected by various factors, such as the property of rock, the viscosities and densities of fluids, the velocity of water injection, and so on [20]. It is also influenced by the gas saturation after the gas injection, hereafter we refer it as the initial gas saturation. Several researchers have carried out the core flooding experiments with sandstone for a supercritical $\mathrm{CO}_{2}$ and water system and found that the residual gas saturation increases with an increasing initial gas saturation [21]-[23]. When the initial gas saturation is low, the residual gas saturation is low. Therefore the trapped gas volume per unit volume of porous rock is also low. However, the moved $\mathrm{CO}_{2}$ saturation, which is the difference between the initial and the residual gas saturations, is also low. The most of the $\mathrm{CO}_{2}$ injected into the porous rock is trapped at the same place by capillarity for low initial gas saturations. On the other hand, for the high initial gas saturations, the residual gas saturation is also high. However, the moved $\mathrm{CO}_{2}$ saturation is also high.

The initial gas saturation at the start of the water inflow is also affected by various factors including the characteristics of porous medium, the viscosity ratio, buoyancy, and capillary forces of the flowing fluids [24]-[27]. At the natural sandstone cores, the initial gas saturation depends on pore size distribution and the heterogeneity caused by the sedimentary layers [23]. The initial gas saturation influences not only the residual gas saturation but also an extent of $\mathrm{CO}_{2}$ plume in the reservoir.

In this research, we investigated the influence of the homogeneity of porous media on the initial gas saturation and the residual gas saturation. When gas permeates into the porous media filled with water, the gas pressure should exceed the capillary entrance pressure. Natural sedimentary formations have stratified structure of porous media. The interface of stratified structure hinders gas migration across it. The effect of the interface on gas vertical and parallel migration was discussed.

\section{Experimental Method}

The glass beads with the particle diameters of $200 \mu \mathrm{m}, 400 \mu \mathrm{m}$, and $600 \mu \mathrm{m}$ were packed in the acrylic cylinder with the inner diameter of $32 \mathrm{~mm}$, as shown in Figure 1, to model the stratified structure of natural sedimentary formations. We made two types of packed beds which have the stratified parallel and vertical structure to the fluid flows, respectively, as shown in Figure 1(a) and Figure 1(b). The packed beds were aligned with respect to the gravitational acceleration. The fluids were injected into these beds vertically upward or downward. The experiments were carried out at atmospheric temperature and pressure conditions. Nitrogen and water doped with $7.5 \mathrm{wt} \%$ sodium iodide were used for fluids, because of the visualization in an X-ray computed tomography (CT) scanner inside of the packed beds.

The characteristics of homogeneous porous media are summarized in Table 1 . The porosity of the packed beds was estimated as 0.38 by the measurement of the mass change before and after water saturation. The permeability is evaluated by Carman-Kozney formulas,

$$
k=\frac{\varphi^{3}}{180(1-\varphi)^{2}} d^{2}
$$

and the Bond number [27] is defined as,

$$
N_{D B}=\frac{\Delta \rho g(k / \varphi)}{\sigma}
$$

where $\phi$ is the porosity, $d$ is the glass beads diameter, $\Delta \rho$ is the density difference, $g$ is the gravitational acceleration, $\sigma$ is the interfacial tension. The Bond number in Table 1 was evaluated for nitrogen and water system used in the experiments. For the typical reservoir conditions of CCS, $N_{D B}$ is approximately $10^{-7}$ for a supercritical $\mathrm{CO}_{2}$ and water system. Therefore, the buoyancy is relatively higher with respect to the capillary forces in the experimental conditions.

The experiments were carried out as following procedures. First, the packed beds were saturated with water by using a vacuum chamber. Second, the gas injection side of the packed bed was connected to the tank filled with nitrogen and another drainage side was connected to a syringe filled with water. Next, the gas was injected into the packed bed at a constant flow rate by withdrawing water by a syringe pump at a constant flow rate. Finally, water was injected into the packed bed at a constant rate. For gas injection, experiments were carried out 


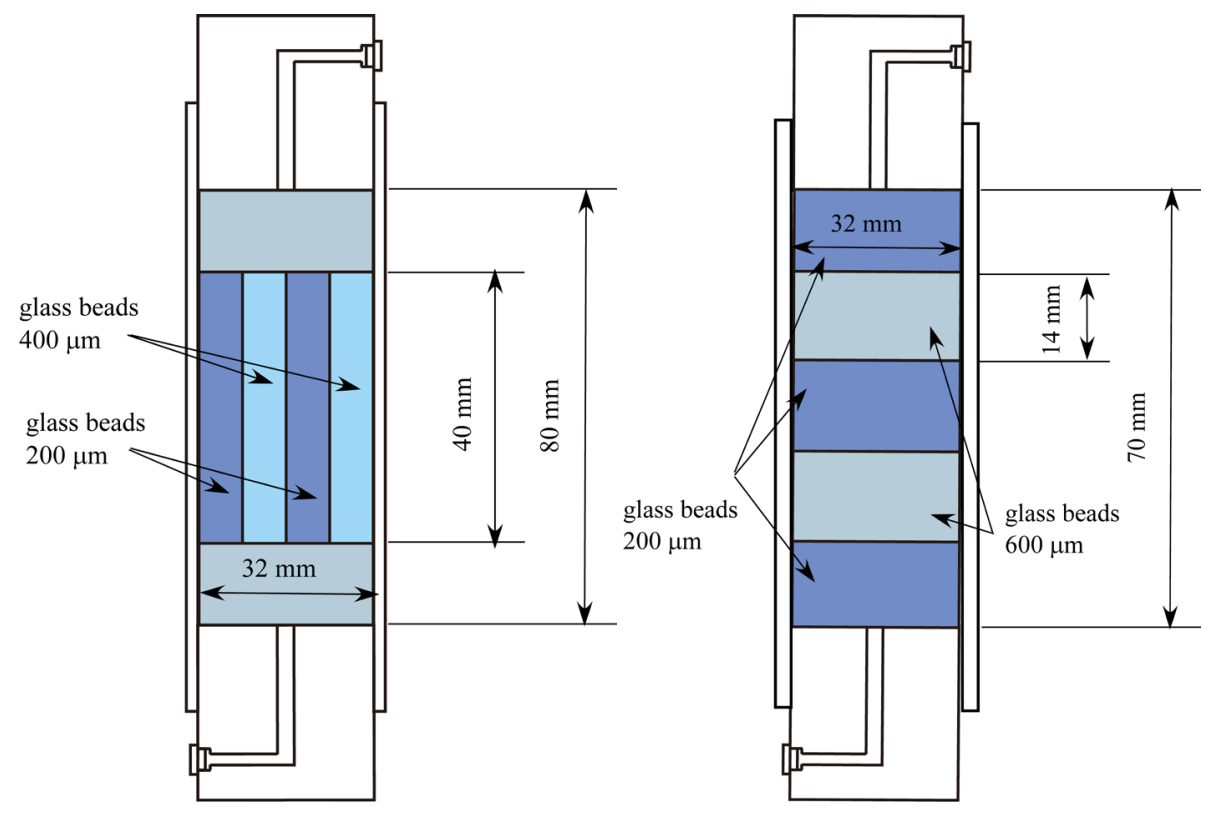

(a)

(b)

Figure 1. Experimental setup. (a) Parallel layers; (b) Serial layers.

Table 1. Properties of porous media.

\begin{tabular}{ccc}
\hline Porous medium & Permeability, $k, \mathrm{~m}^{2}$ & Bond number, $N_{D B},-$ \\
\hline $200 \mu \mathrm{m}$ & $3.17 \times 10^{-11}$ & $1.123 \times 10^{-5}$ \\
$400 \mu \mathrm{m}$ & $1.27 \times 10^{-10}$ & $4.492 \times 10^{-5}$ \\
$600 \mu \mathrm{m}$ & $2.85 \times 10^{-10}$ & $1.011 \times 10^{-4}$ \\
Berea sandstone, & $9.87 \times 10^{-14}$ & $\approx 10^{-7}$ \\
$\varphi=0.20$, sc. $\mathrm{CO}_{2}$ & & \\
\hline
\end{tabular}

at three capillary numbers $\left(\mathrm{Ca}=\mu_{w} u / \sigma\right)$ of $1.0 \times 10^{-7}, 1.0 \times 10^{-6}$, and $1.0 \times 10^{-5}$, where $\mu_{w}$ denotes the viscosity of water, $u$ is the Darcy velocity that is defined as the volumetric flow rate per unit cross-section area. The gas injection direction was vertically downward and upward. On the one hand, the direction of the water injection was always upward at $\mathrm{Ca}=1.0 \times 10^{-6}$. The volumes of injected gas and water were 1 pore volume $(=21.38 \mathrm{ml})$, respectively. An X-ray CT scanner (Comscantechno Co. Ltd., ScanXmate-G100S110), that was used in our previous work [28], was used to visualize the inside of the packed beds. The pictures were taken at each step of experimental procedures. The size of pictures is $496 \times 496 \times 496$ pixel at the resolution of $70 \mu \mathrm{m} / \mathrm{pixel}$. CT images were adjusted in order that the brightness of the pipe of the packed bed remains same from scan to scan. Because the threshold value of the brightness to distinguish nitrogen gas from water and porous matrix imparts significant impacts on the accuracy of saturation measurements [28], it is decided so that the porosity estimated from the CT images is as close as that evaluated by the change in mass. The maximum difference between the porosity estimated from the CT images and that from the change in mass was 0.03 which is included also in the measurement of saturation.

\section{Results and Discussion}

\subsection{Parallel Layer}

Figure 2 and Figure 3 show the distributions of gas in porous media at initial gas conditions after the downward gas injection into the parallel layer, and at the residual gas trapping conditions after water injection, respectively. Commercial software (VG Studio Max 2.1) was used to draw 3-D images from the CT images. At each capillary number, gas penetrated only through the layer of $400 \mu \mathrm{m}$. Gas can hardly enter layer of 200 $\mu \mathrm{m}$, because the entrance pressure was twice higher than that of $400 \mu \mathrm{m}$. Because the gas flowed only 


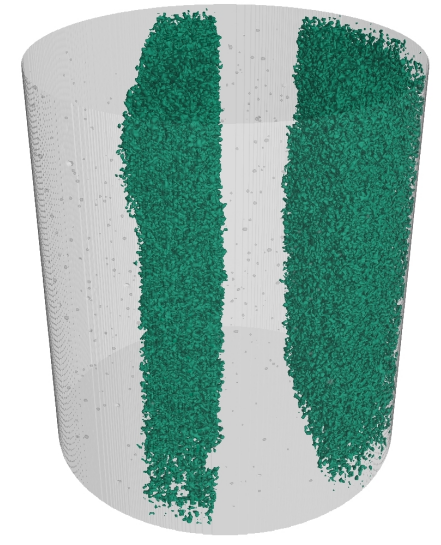

(a)

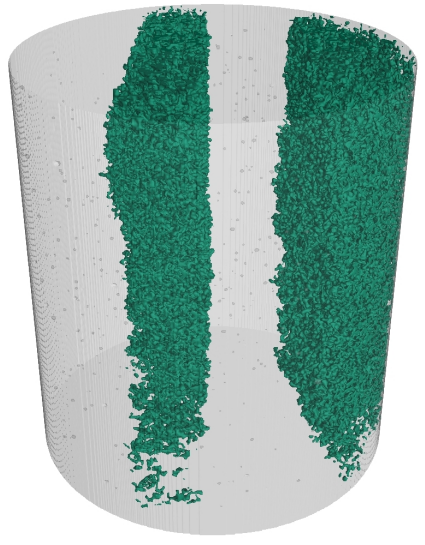

(b)

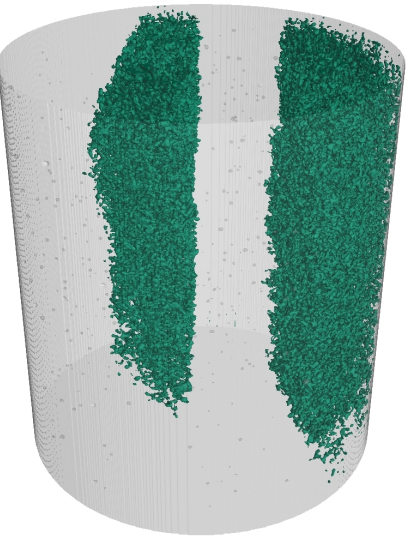

(c)

Figure 2. Downward gas injection into parallel structures. Surfaces of gas bubbles are colored in green. The porous media consist of four parallel layers of $200 \mu \mathrm{m}, 400 \mu \mathrm{m}, 200 \mu \mathrm{m}$, and $400 \mu \mathrm{m}$ from left to right. The visualized cylindrical region is $35.6 \mathrm{~mm}$ in height and $32.0 \mathrm{~mm}$ in diameter. (a) $\mathrm{Ca}=1.0 \times$ $10^{-7}$; (b) $\mathrm{Ca}=1.0 \times 10^{-6}$; (c) $\mathrm{Ca}=1.0 \times 10^{-5}$.

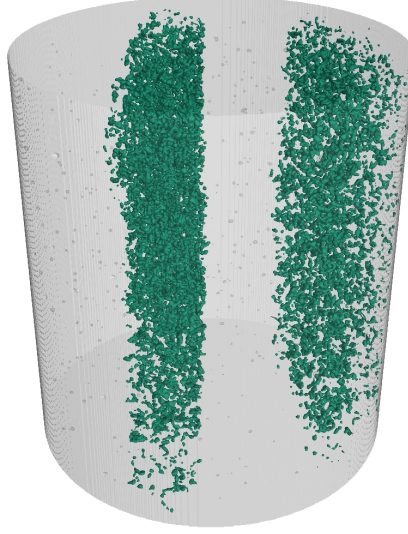

(a)

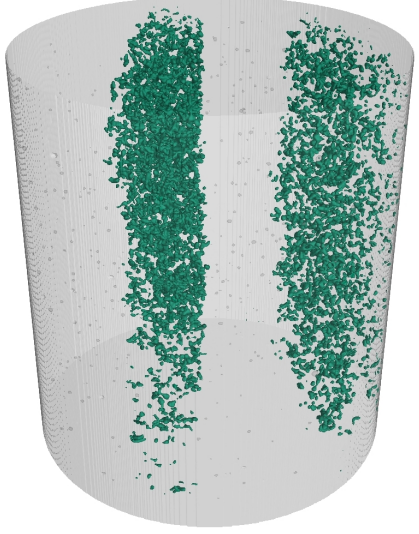

(b)

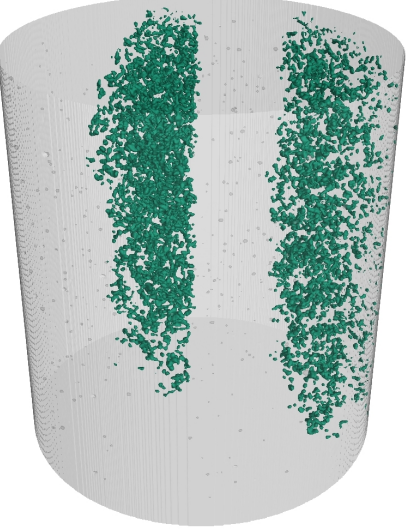

(c)

Figure 3. Trapped gas bubbles after upward imbibition of water into the initial gas condition shown in Figure 2. (a) $\mathrm{Ca}=1.0 \times 10^{-7}$; (b) $\mathrm{Ca}=1.0 \times 10^{-6}$; (c) $\mathrm{Ca}=1.0 \times 10^{-5}$.

through the layer of $400 \mu \mathrm{m}$, the effective cross-sectional area substantially reduced by half. Additionally, the amount of gas penetration into two layers of $400 \mu \mathrm{m}$ was different from each other. The amount of gas percolation in right layer in Figure 2 was higher than the other because the gas migration stopped in the left layer after the breakthrough in the right layer.

Figure 3 shows the gas was trapped at the position where gas percolated during the gas injection. Throughout the processes of drainage and imbibition, the layers of $200 \mu \mathrm{m}$ were always saturated with water, and did not contribute as a gas reservoir. As shown in homogeneous packed bed of glass beads [25], the various sizes of the trapped gas bubbles were observed in Figure 3 from small bubbles at a pore scale to large bubbles at a pore network scale.

Figure 4 shows the initial gas condition after the upward gas injection into the parallel layer. In this case, viscous fingering and/or capillary fingering [29]-[33] caused at the interface between gas and water enhanced by buoyancy. Therefore, the gas fingers penetrated one layer of $400 \mu \mathrm{m}$ creating slight route. The initial gas saturation after gas injection was low compared with the downward cases shown in Figure 2, where the fingerings are suppressed by the buoyancy. In the case of upward injection, the initial gas saturation tends to increase with the capillary number because of the pressure gradient established along the flow direction [24] [25]. In the case of downward injection, the gas saturation tends to decrease with the capillary number because 


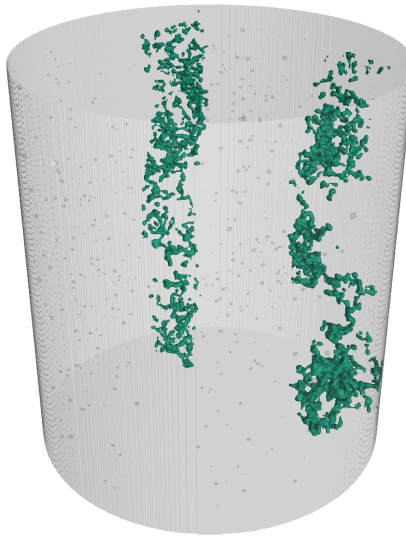

(a)

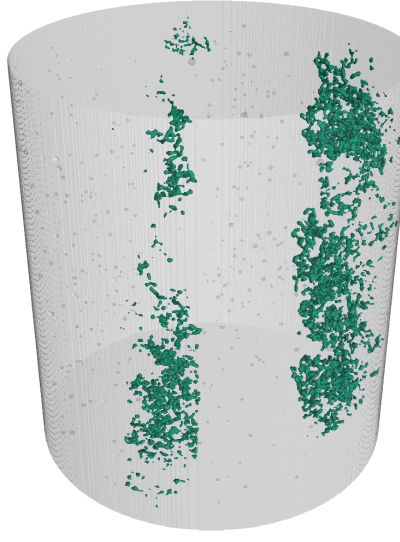

(b)

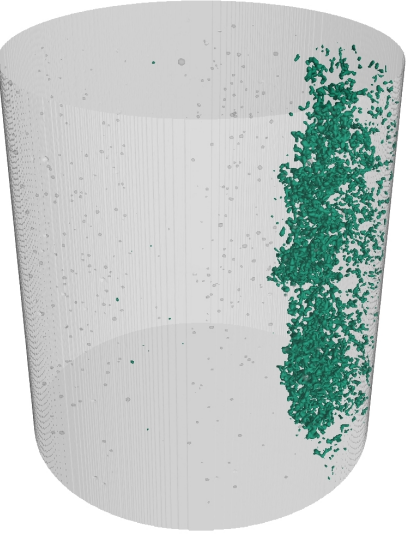

(c)

Figure 4. Upward gas injection into parallel structures. (a) $\mathrm{Ca}=1.0 \times 10^{-7}$; (b) $\mathrm{Ca}=1.0 \times 10^{-6}$; (c) Ca $=1.0 \times 10^{-5}$.

of the instability on the interface [27].

\subsection{Serial Layer}

Figure 5 and Figure 6 show the images of the initial gas state and the residual gas trapping state at the capillary number of $1.0 \times 10^{-7}$ for gas injection into the serial layers in a downward and upward direction, respectively. In the case of a downward gas injection, the interface between gas and water was stabilized by buoyancy, but the displacement efficiency was different from each other between the layers of $200 \mu \mathrm{m}$ and $600 \mu \mathrm{m}$. The initial gas saturation for $200 \mu \mathrm{m}$ was lower than that of $600 \mu \mathrm{m}$. At the early state of gas percolation in the layer of $600 \mu \mathrm{m}$, it would be expected that the percolation pattern was same with that of $200 \mu \mathrm{m}$. During this stage, the pressure gradient was kept low through the packed bed. When the tip of the finger reached the interface bottom of the $600 \mu \mathrm{m}$ layer, the capillary entrance pressure of the $200 \mu \mathrm{m}$ layer hindered the percolation into the $200 \mu \mathrm{m}$ layer. Therefore, fingers grew in radial directions in $600 \mu \mathrm{m}$ layer after the pressure built up to overcome the entrance pressure. On the other hand, when the finger grew in the layer of $200 \mu \mathrm{m}$, there was no entrance pressure for $600 \mu \mathrm{m}$. Therefore, when a finger reached the interface, it spontaneously percolated into the $600 \mu \mathrm{m}$ layer. As a result, much gas penetrated into the layer of $600 \mu \mathrm{m}$ even for the upward gas injection as shown in Figure 6. For the layer of $200 \mu \mathrm{m}$, because the percolation process was same with homogeneous packed bed, the initial gas saturation of this layer was lower for upward injection because of enhanced fingering.

In the residual gas trapping condition, a large amount of gas was trapped in the high gas saturation layers of $600 \mu \mathrm{m}$. For the layers of $600 \mu \mathrm{m}$, all the downstream layers were $200 \mu \mathrm{m}$ for upward injection of water. For the gas in $600 \mu \mathrm{m}$, the interface acted as a trapping structure due to the capillary entrance pressure. Therefore, the gas saturation was high at the layer of $600 \mu \mathrm{m}$.

\subsection{Local Initial Gas Saturation}

For inhomogeneous packed beds, the gas saturation changed from layers to layers. Therefore, we evaluated the local initial gas saturation for each layer. In the parallel layer, the average gas saturation was evaluated in the region from the entrance to the position of $15 \mathrm{~mm}$. In the serial layer, the gas saturation was evaluated for three layers of $600 \mu \mathrm{m}$ and only the middle $200 \mu \mathrm{m}$ layer. Figure 7 and Figure 8 show the initial gas saturation for each layer as a function of capillary number with the data for homogeneous packed beds for downward and upward gas injection, respectively.

In the case of downward gas injected into the parallel layer, the gas flowed only through the layer of $400 \mu \mathrm{m}$, because of the capillary entrance pressure as mentioned above. The initial gas saturation at the layer of $400 \mu \mathrm{m}$ for the parallel layers agrees well with that at the homogeneous packed bed of $400 \mu \mathrm{m}$. In the case of upward gas injection, the viscous and/or capillary fingering was enhanced by buoyancy. Therefore the initial gas saturation 


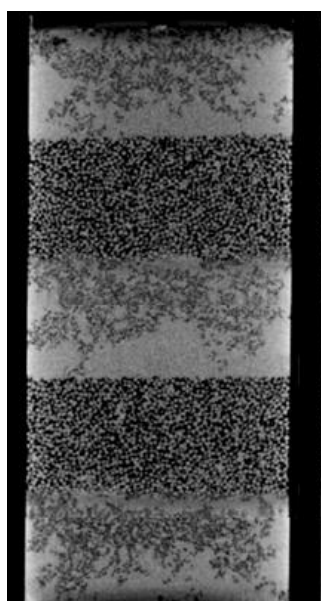

(a)

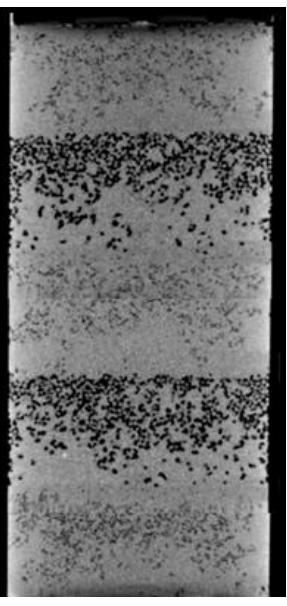

(b)

Figure 5. Effect of serial heterogeneity of porous media on gas saturations for downward gas injection at the capillary number of $1.0 \times 10^{-7}$. Porous media consist of five layers of $200 \mu \mathrm{m}, 600 \mu \mathrm{m}, 200 \mu \mathrm{m}$, $600 \mu \mathrm{m}$, and $200 \mu \mathrm{m}$ from the top to the bottom. Dark region denotes gas gray region denotes glass beads filled with water. (a) Initial gas state; (b) Residual gas state.

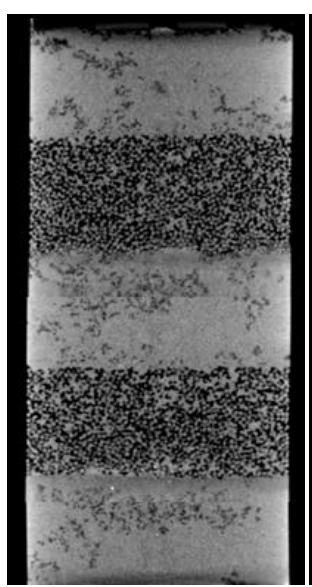

(a)

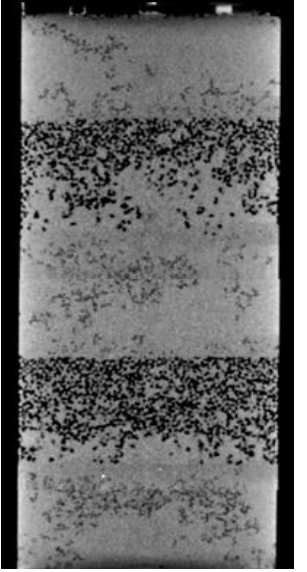

(b)

Figure 6. Effect of serial heterogeneity of porous media on gas saturations for upward gas injection at the capillary number of $1.0 \times 10^{-7}$. (a) Initial gas state; (b) Residual gas state.

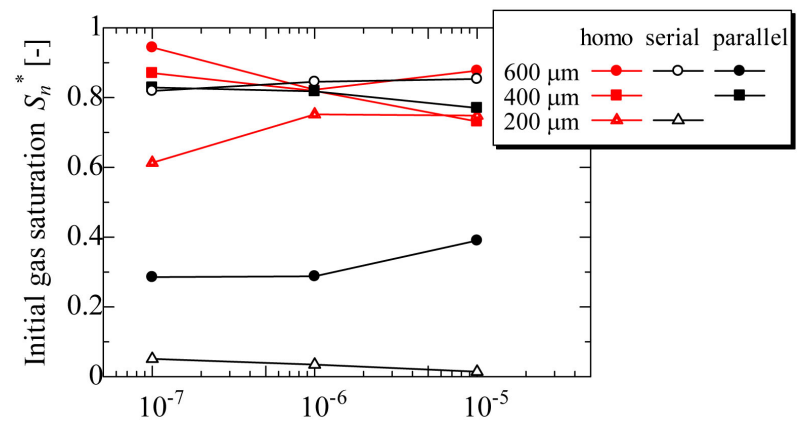

Gas injection Capillary number [-]

Figure 7. Effect of heterogeneity and capillary number on the gas saturation after downward gas injection. 


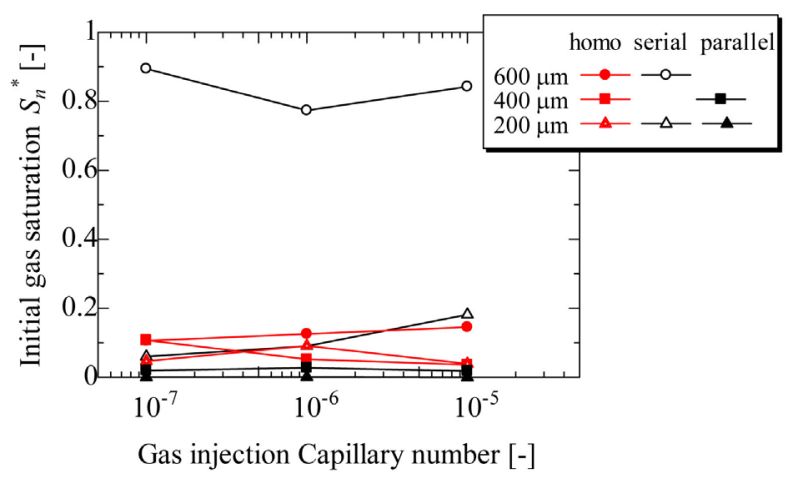

Figure 8. Effect of heterogeneity and capillary number on the gas saturation after upward gas injection.

for the layer of $400 \mu \mathrm{m}$ was very low for all capillary numbers. The initial gas saturation at the layer of $400 \mu \mathrm{m}$ agrees well with that at the homogeneous packed bed. It should be noted that the parallel packed bed consisted of the layers of $400 \mu \mathrm{m}$ and $200 \mu \mathrm{m}$, and the gas saturation was always zero for the layer of $200 \mu \mathrm{m}$. The heterogeneity parallel to the flow direction reduces the pore space capacity for gas migration.

In the gas injected to a downward direction into the serial layer, the gas saturation was determined by the downstream capillary entrance pressure rather than the property of local porous media as mentioned above. Therefore, gas saturation for the $600 \mu \mathrm{m}$ layer was high because of the capillary entrance pressure behind this layer. The initial gas saturation at the $600 \mu \mathrm{m}$ layer was as high as that for the homogeneous packed bed. For the $200 \mu \mathrm{m}$ layer, when the finger reaches the $600 \mu \mathrm{m}$, it spontaneously percolated into the $600 \mu \mathrm{m}$ layer as mentioned above. As a result, the saturation at the $200 \mu \mathrm{m}$ layer is much lower than that for the homogeneous packed bed.

On the other hand, in the case of upward gas injection as shown in Figure 8, the gas saturations of homogeneous layer were lower than 0.2 , because the viscous and/or capillary fingering was enhanced by the buoyancy. With the increase in the capillary number, the pressure gradient established across the beds was high. The gas saturation, however, remained low in the range of the capillary number between $10^{-7}$ and $10^{-5}$. In the case of serial layer, the initial gas saturations at the layer of $600 \mu \mathrm{m}$ were more than 0.7 for all capillary numbers. This fact suggests that high gas saturation is expected when injected $\mathrm{CO}_{2}$ migrates across the sedimentary layers due to buoyancy force. For the layer of $200 \mu \mathrm{m}$, the initial gas saturations were as high as those for the homogeneous packed bed, because of no entrance pressure.

\subsection{Residual Gas Saturation}

To evaluate storage capacity of $\mathrm{CO}_{2}$ in inhomogeneous porous media, the saturation should be evaluated averaged over the inhomogeneous structures. In the parallel layers, the average saturation was evaluated in the region from the inlet to the position of $15 \mathrm{~mm}$ including four layers. In the serial layers, the average gas saturation of $600 \mu \mathrm{m}$ and $200 \mu \mathrm{m}$ was evaluated. These results are shown in Figure 9 for all capillary numbers.

In the parallel layer, when the gas was injected in an upward direction, both the initial gas saturation and residual gas saturation were low. When the gas was injected in a downward direction, the initial gas saturation increased up to $30 \%$; but the residual gas saturation remained still low, because the gas entered only in high penetration layers. This fact suggests that $\mathrm{CO}_{2}$ has a potential to migrate through the vertical faults selectively at low saturation.

On the other hand, in the serial layer, the initial gas saturation was approximately $60 \%$ for the downward injection, and approximately 50\% for the upward injection. The residual gas saturations both upward and downward injections were approximately $30 \%$. But, the residual gas saturation was a little different between upward and downward. When $\mathrm{CO}_{2}$ was injected into the geological formations, the stratified structure reduced the development of the viscous and/or capillary fingering.

\section{Conclusions}

We have investigated the effect of stratified structure of heterogeneous porous media on gas permeation and 


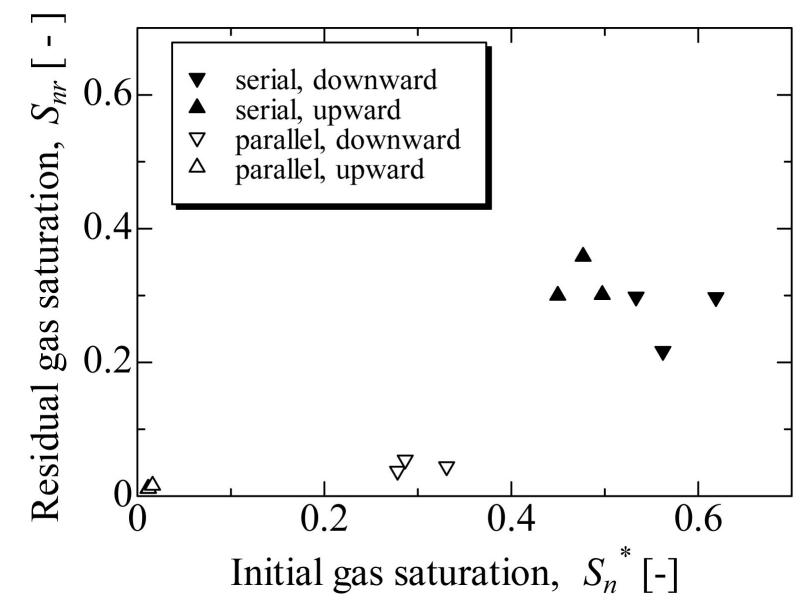

Figure 9. Relationship between the initial gas saturation and the residual gas saturation.

entrapment. Experiments were carried out at a laboratory condition for a nitrogen and water system with the packed beds of glass beads with various diameters which modeled stratified porous media.

In the case of parallel structure, the injected gas selectively percolated into permeable layers. The gas permeation can hardly occur for the less permeable layers because of the capillary entrance pressure. For the permeable layers, the initial gas saturation was higher for the downward gas injection compared with the upward injection, because buoyancy suppresses the development of fingering. The interface of porous structure does not contribute to the residual gas trapping. Therefore the residual gas saturations were low for both cases.

In the case of serial structure, the interface of porous structure hindered the migration of gas across it, because of the capillary entrance pressure. When the gas percolated in the permeable layers, capillary fingering was developed in the layers. However, when the tip of finger reached the interface, fingers grew in tangential directions until the pressure built up to overcome the capillary entrance pressure. As a result, high gas saturation was achieved in the permeable layers of both upward and downward gas injections. In imbibition process, the interface acted as the trapping structure by capillarity. Therefore, high residual gas saturation was achieved in the permeable layers.

\section{Acknowledgements}

We used the X-ray CT scanner at the JST Tokushima Plaza in the University of Tokushima. This work was supported by JSPS KAKENHI Grant Number 21310053.

\section{References}

[1] Juans, R., Spiteri, E.J., Orr Jr., F.M. and Blunt, M.J. (2006) Impact of Relative Permeability Hysteresis on Geological $\mathrm{CO}_{2}$ Storage. Water Resource Research, 42, W12418.

[2] Flett, M., Gurton, R. and Weir, G. (2007) Heterogeneous Saline Formations for Carbon Dioxide Disposal: Impact of Varying Heterogeneity on Containment and Trapping. Journal of Petroleum Science and Engineering, 57, 106-118. http://dx.doi.org/10.1016/j.petrol.2006.08.016

[3] Qi, R., LaForce, T.C. and Blunt, M.J. (2009) Design of Carbon Dioxide Storage in Aquifers. International Journal of Greenhouse Gas Control, 3, 195-205. http://dx.doi.org/10.1016/j.ijggc.2008.08.004

[4] Suekane, T., Nobuso, T., Hirai, S. and Kiyota, M. (2008) Geological Storage of Carbon Dioxide by Residual Gas and Solubility Trapping. International Journal of Greenhouse Gas Control, 2, 58-64. http://dx.doi.org/10.1016/S1750-5836(07)00096-5

[5] Suekane, T., Zhou, N., Hosokawa, T. and Matsumoto, T. (2010) Direct Observation of Gas Bubbles Trapped in Sandy Porous Media. Transport in Porous Media, 82, 111-122. http://dx.doi.org/10.1007/s11242-009-9439-5

[6] Wildenschild, D., Armstrong R.T., Herring, A.L., Young, I.M. and Carey, J.W. (2010) Exploring Capillary Trapping Efficiency as a Function of Interfacial Tension, Viscosity, and Flow Rate. Energy Procedia, 4, 4945-4952. http://dx.doi.org/10.1016/j.egypro.2011.02.464 
[7] Zhou, N., Matsumoto, T., Hosokawa, T. and Suekane, T. (2010) Pore-Scale Visualization of Gas Trapping in Porous Media by X-Ray CT Scanning. Flow Measurement and Instrumentation, 21, 262-267. http://dx.doi.org/10.1016/j.flowmeasinst.2010.05.002

[8] Al Mansoori, S.K., Itsekiri, E., Iglauer, S., Pentland, C.H., Bijeljic, B. and Blunt, M.J. (2010) Measurements of NonWetting Phase Trapping Applied to Carbon Dioxide Storage. International Journal of Greenhouse Gas Control, 4, $283-$ 288. http://dx.doi.org/10.1016/j.ijggc.2009.09.013

[9] Pentland, C.H., Itsekiri, E., Al-Mansoori, S., Iglauer, S., Bijeljic, B. and Blunt, M.J. (2010) Measurement of Non-Wetting Phase Trapping in Sandpacks. SPE Journal, 15, 274-281. http://dx.doi.org/10.2118/115697-PA

[10] Zhang, D. and Song, J. (2014) Mechanisms for Geological Carbon Sequestration. Prociedia IUTAM, 10, 319-327. http://dx.doi.org/10.1016/j.piutam.2014.01.027

[11] Ennis-King, J. and Paterson, L. (2003) Rate of Dissolution Due to Convective Mixing in the Underground Storage of Carbon Dioxide. Proceedings of 6th International Conference on Greenhouse Gas Control Technologies, 1, 507-510. http://dx.doi.org/10.1016/B978-008044276-1/50081-7

[12] Lindeberg, E. and Wessel-Berg, D. (1997) Vertical Convection in an Aquifer Column under a Gas Cap of $\mathrm{CO}_{2}$. Energy Conversion and Management, 38, S229-S234. http://dx.doi.org/10.1016/S0196-8904(96)00274-9

[13] Bachu, S. and Adams, J.J. (2003) Sequestration of $\mathrm{CO}_{2}$ in Geological Media in Response to Climate Change: Capacity of Deep Saline Aquifer to Sequester $\mathrm{CO}_{2}$ in Solution. Energy Conversion and Management, 44, 3151-3175. http://dx.doi.org/10.1016/S0196-8904(03)00101-8

[14] Ennis-King, J.K., Preston, I. and Paterson L. (2005) Onset of Convention in Anisotropic Porous Media Subject to a Rapid Change in Boundary Conditions. Physics of Fluids, 17, 084107. http://dx.doi.org/10.1063/1.2033911

[15] Pruss, K. and Nordbotten, J. (2011) Numerical Simulation Studies of the Long-Term Evolution of a $\mathrm{CO}_{2}$ Plume in a Saline Aquifer with a Sloping Caprock. Transport in Porous Media, 90, 135-151. http://dx.doi.org/10.1007/s11242-011-9729-6

[16] Pau, G.S.H., Bell, J.B., Pruss, K., Almgren, A.S., Lijewski, M.J. and Zhan, K. (2010) High-Resolution Simulation and Characterization of Density-Driven Flow in $\mathrm{CO}_{2}$ Storage in Saline Aquifers. Advances in Water Resources, 33, 443455. http://dx.doi.org/10.1016/j.advwatres.2010.01.009

[17] MacMinn, C.W., Szulczewski, M.L. and Juanes, R. (2011) $\mathrm{CO}_{2}$ Migration in Saline Aquifer. Part 2. Capillary and Solubility Trapping. Journal of Fluid Mechanics, 688, 321-351.http://dx.doi.org/10.1017/jfm.2011.379

[18] Rochelle, C.A., Czernichowski-Lauriol, I. and Milodowski, A.E. (2004) The Impact of Chemical Reactions on $\mathrm{CO}_{2}$ Storage in Geological Formations: A Brief Review. Geological Society, London, Special Publications, 233, 87-106.

[19] Espinoza, D.N., Kim, S.H. and Santamarina, J.C. (2011) $\mathrm{CO}_{2}$ Geological Storage-Geotechnical Implications. KSCE Journal of Civil Engineering, 15, 707-719. http://dx.doi.org/10.1007/s12205-011-0011-9

[20] Holtz, M.H. (2002) Residual Gas Saturation to Aquifer Influx: A Calculation Method for 3-D Computer Reservoir Model Construction. SPE Gas Technology Symposium, Calgary, 30 April-2 May 2002, Article ID: SPE-75502-MS. http://dx.doi.org/10.2118/75502-MS

[21] Pentland, C.H., El-Maghraby, R., Iglauer, S. and Blunt, M.J. (2011) Measurement of the Capillary Trapping of SuperCritical Carbon Dioxide in Berea Sandstone. Geophysical Research Letters, 38, Published Online. http://dx.doi.org/10.1029/2011GL046683

[22] El-Maghraby, R. and Blunt, M.J. (2012) Residual $\mathrm{CO}_{2}$ Trapping in Indiana Limestone. Environmental Science \& Technology, 47, 227-233.

[23] Suekane, T. and Nguyen, H.T. (2013) Relation between the Initial and Residual Gas Saturations of Gases Trapped by Capillarity in Natural Sandstone. Journal of Fluid Science and Technology, 8, 322-336. http://dx.doi.org/10.1299/jfst.8.322

[24] Suekane, T. and Ushita, H. (2011) Effect of Buoyancy on Pore-Scale Characteristics of Two-Phase Flow in Porous Media. In: Saba, L., Ed., Computed Tomography—Special Applications, Intech, 179-194.

[25] Suekane, T. and Okada, K. (2013) Gas Injection in a Water Saturated Porous Medium: Effect of Capillarity, Buoyancy, and Viscosity Ratio. Energy Procedia, 37, 5545-5552. http://dx.doi.org/10.1016/j.egypro.2013.06.475

[26] Ferer, M., Anna, S.L., Tortora, P., Kadambi, J.R., Oliver, M., Bromhal, G.S. and Smith, D.H. (2011) Two-Phase Flow in Porous Media: Predicting Its Dependence on Capillary Number and Viscosity Ratio. Transport in Porous Media, 86, 243-259. http://dx.doi.org/10.1007/s11242-010-9619-3

[27] Rostami, B., Kharrat, R., Pooladi-Darvish, M. and Ghotbi, C. (2010) Identification of Fluid Dynamics in Forced Gravity Drainage Using Dimensionless Groups. Transport in Porous Media, 83, 725-740. http://dx.doi.org/10-1007/s11242-009-9478-y

[28] Setiawan, A., Suekane, T., Deguchi, Y. and Kusano, K. (2014) Three-Dimensional Imaging of Pore-Scale Water 
Flooding Phenomena in Water-Wet and Oil-Wet Porous Media. Journal of Flow Control, Measurement \& Visualization, 2, 25-31. http://www.dx.doi.org/104236/jfcmv.2014.22005

[29] Lenomand, R., Touboul, E. and Zarcone, C. (1988) Numerical Models and Experiments on Immiscible Displacements in Porous Media. Journal of Fluid Mechanics, 189, 165-187. http://dx.doi.org/10.1017/S0022112088000953

[30] Homsy, G.M. (1987) Viscous Fingering in Porous Media. Annual Review of Fluid Mechanics, 19, 172-311. http://dx.doi.org/10.1146/annurev.fl.19.010187.001415

[31] Måløy, K.J., Feder, J. and Jøssang, T. (1985) Viscous Fingering Fractals in Porous Media. Physical Review Letters, 55, 2688. http://dx.doi.org/10.1103/PhysRevLett.55.2688

[32] Wilkinson, D. and Willemsen, J.F. (1983) Invasion Percolation: A New Form of Percolation Theory. Journal of Physics A, 16, 3365.

[33] Furuberg, L., Feder, J., Aharony, A. and Jøssang, T. (1988) Dynamics of Invasion Percolation. Physical Review Letters, 61, 2117. http://dx.doi.org/10.1103/PhysRevLett.61.2117 
Scientific Research Publishing (SCIRP) is one of the largest Open Access journal publishers. It is currently publishing more than 200 open access, online, peer-reviewed journals covering a wide range of academic disciplines. SCIRP serves the worldwide academic communities and contributes to the progress and application of science with its publication.

Other selected journals from SCIRP are listed as below. Submit your manuscript to us via either submit@scirp.org or Online Submission Portal.
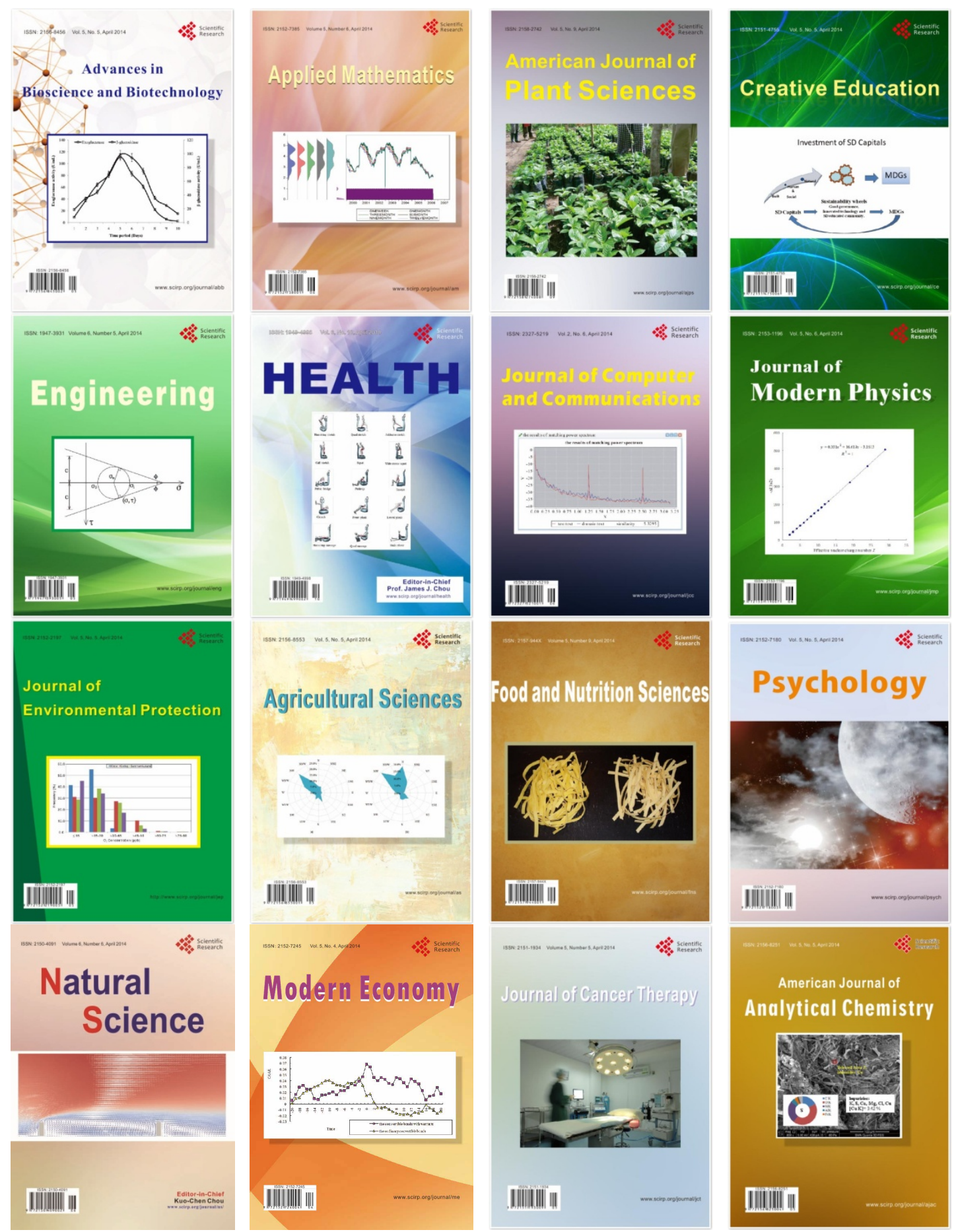